\title{
Cultivating Employee Engagement in Organizations: Development of a Conceptual Framework
}

\author{
Susan Zeidan ${ }^{1}$, Noura Itani
}

Submitted: 31.12.2019. Accepted: 21.03.2020

\section{Abstract}

Purpose: Despite the popularity of employee engagement in the past decade, organizations across the globe struggle with disengaged employees at work. The purpose of this paper is to critically reflect on issues relating to employee engagement and to develop a conceptual framework that explains the linkages between organizational climate, procedural justice, distributive justice, perceived organizational support, and employee engagement with the aim of fostering higher levels of employee engagement in organizations.

Methodology: The paper provides a systematic review of the literature on employee engagement and reviews from peer-reviewed journals written in English on the topic and published in 1985-2019.

Findings: Research in this field shows that engaged employees are perceived as employees who work harder, are willing to go the extra mile, and are more passionate about the work they do and the quality they present to produce better results that drive business growth. Today, more than ever, organizations understand the importance of their employees and view them as the most important asset to their businesses. Hence, keeping employees committed and engaged has become one of the key focuses for organizations.

Originality: Previous studies have not considered a holistic model of employee engagement from the angles addressed in this paper nor has such a model been tested on a global or regional scale. This study contributes to the literature on employee engagement by proposing a conceptual framework through which organizations can have important insights into how to engage their employees. The conceptual framework of this study will be crucial for organizations attempting to improve their employee engagement.

Keywords: employee engagement, organizational climate, distributive justice, procedural justice, perceptions of organizational support

JEL: 015, J24

1 Amity University Dubai, Department of Management and Commerce, Dubai; e-mail: szeidan@amityuniversity.ae; https://orcid.org/0000-0002-3447-5069.

2 Scholar, nouraitani@hotmail.com. 


\section{Introduction}

Many organizations recognize that employees are their best assets that allow them to better compete in the marketplace to achieve competitive advantage (Bailey et al., 2016). In today's ever-changing business world, employee motivation goes beyond salaries. Employees now anticipate that their role should contribute to and affect the business in a greater sense (Marciano, 2010). This has altered the focus of employers to allow them to better understand the true essence of what fosters employee engagement.

Research on employee engagement (EE) is of high importance to managers, because disengaged employees are employees who lack commitment and motivation (Aktouf, 1992). Employees non-engaged in their work lead to lower productivity and profitability (Scott, 2017). Hence, many place a strong emphasis on defining and measuring employee engagement as well as understanding the impact of its antecedents. According to a 2017 survey by Gallup (pg. 53), 85\% of employees are non-engaged or actively disengaged in their jobs, uninvolved in their work, and their workplace. The Gallup research aimed to understand the reasons behind low productivity and the lack of engagement in the workplace and how organizations can improve these factors. The Gallup study collected data with the use of surveys from over 140 countries over the course of a five-year period to determine employee engagement and its impact on business outcomes. The survey also assessed engagement levels geographically and revealed that the Middle East and North Africa have the highest level of actively disengaged employees, reaching $22 \%$ of non-engaged employees. This figure is alarming, especially taking into consideration that improving employee engagement has become one of the biggest concerns of employers as research shows that their overall productivity and profitability clearly depend on employee engagement.

Branham (2005) argues that disengaged employees have a negative impact on both organizational morale and profitability. Moreover, according to the Workplace Research Foundation, engaged employees are likely to be $38 \%$ more productive than non-engaged employees. In agreement, Choudhury and Mohanty's (2019) study reveals that the level of engagement in an organization leads to increased productivity, reduced turnover, improved job performance, and many other desirable outcomes. This agrees with many other researchers who show a strong positive correlation between employee engagement and organizational outcomes (Choudhury and Mohanty, 2019) such as the increased performance (Smith and Bittci, 2017), productivity (Mohanty et al., 2018), and profitability (Zelles, 2015) of an organization. Kruger and Killham (2007) also state that disengaged employees are less involved and tend not to share innovative and creative ideas with coworkers. Thus, it becomes imperative to further investigate factors that 
could foster employee engagement. This study attempts to address this issue by developing a framework that could have practical implications in organizations, especially in the Middle East and North Africa, as this region seems to have the highest level of non-engaged employees.

Luthans and Peterson (2002) argue that managers must create an engaging environment for their employees, both emotionally and cognitively. Managers should showcase empathy and concern toward their employees, all while providing them with a purpose for their work and focusing on their contribution to the business. Luthans and Peterson (2002) suggest that the healthier and stronger the employee-manager relationship is, the more emotionally engaged the employees will be, and the more likely they are to provide positive outcomes and support their managers. Similarly, those employees produce greater results who are clear on what is expected of them, understand their purpose, and are cognitively stimulated. Several studies underline the importance of employee engagement on both the individual and organizational levels. The resulting impact improves customer satisfaction, increases retention rates, and enhances productivity and profitability. Moreover, scholars correlate employee engagement with employee well-being, increased performance, and reduced turnover (Christian et al., 2011; Halbesleben, 2010). In addition to supervisor support, other factors play a role in engaging employees, such as perceived organizational support, organizational culture, and organizational justice. Furthermore, it has been revealed that promoting an environment of social-bonding and camaraderie in an organization can help increase employee engagement (Bhappu and Schultze, 2018).

This study contributes to the literature on employee engagement by proposing a conceptual framework through which organizations can gain important insights into how to engage their employees. We propose procedural justice, distributive justice, perceived organizational support, and organizational climate as the main variables in our framework for influencing employee engagement. Furthermore, we argue that organizational climate plays a mediating role in the relationship between perceived organizational support and employee engagement. The conceptual framework of this study will be crucial for organizations attempting to improve their employee engagement levels, as it offers a starting point whose variables managers should consider addressing first.

This research offers diverse contributions to the literature, as it can help organizations improve their overall performance and maintain a competitive edge. First, the proposed conceptual framework expands the scope of employee's perception of managers and the organization and how the perceptions can affect employee engagement levels. Second, we shed light on a gap found in both the academic and professional worlds. 
Third, we investigate in-depth the variables included in the framework we developed to understand the implications they have on the engagement levels in organizations. In addition, our research highlights the significance of the mediating role of organizational climate on employee engagement, which has not been adequately explored.

Previous studies did not consider a holistic model of employee engagement from the angles addressed in this paper, nor has such a model been tested on a global or regional scale. Therefore, there is a significant need for this framework to be tested, especially by focusing on regions with the lowest levels of employee engagement, such as the Middle East, as there is a shortage in theoretical arguments and empirical evidence in this regard.

Following the introduction, we provide a literature review in which we discuss employee engagement, its definitions, antecedents, and outcomes. Then, we provide a theoretical background from which we developed our conceptual model. Thereafter, we provide propositions based on our model to be tested by forthcoming empirical studies, followed by a conclusion and directions for future research.

\section{Literature Review}

\section{Defining Employee Engagement}

Research on employee engagement shows a clear overlap with other variables, including affective commitment, organizational citizenship behavior, and psychological contracts. There are many differences in how the concept of employee engagement is defined in the literature. Some define it in a way similar to psychological contracts, specifying that it is an unwritten two-way relationship between both the employer and the employee that can be easily broken. Others take engagement a step further than employee commitment and argue that engaged employees must appreciate the business and believe that the changes they make to their jobs could positively affect business profitability. For example, a psychological contract was revealed to be a vital aspect of employee engagement where the level of trust, support, and information exchange were all seen as variables with a significant impact on engagement (Lodha and Pathak, 2017). Moreover, psychological contract breach or fulfillment directly impacts employee engagement, as it is an important determinant to the level of employee contribution to the organization (Zeidan, 2006). Employees contribute less if trust is damaged, and hence productivity declines drastically (Naidoo et al., 2019).

Robinson, Perryman, and Hayday (2004) argue that although engagement includes some elements of both organizational citizenship behavior and commitment, which 
do not mirror the two aspects of engagement related to its two-way nature and the fact that engaged employees are supposed to have a facet of business appreciation. Organizational citizenship behavior means the degree to which employees believe in the vision and mission of the organization and feel a sense of belonging to it. The authors define engagement as

a positive attitude held by the employee towards the organization and its values. An engaged employee is aware of business context, and works with colleagues to improve performance within the job for the benefit of the organization. The organization must work to nurture, maintain and grow engagement, which requires a two-way relationship between employer and employee (Robinson, Perryman and Hayday, 2004, p. 19).

Kumar (2015) also regards engagement as a multidimensional construct that groups various aspects of employee attitudes and behaviors toward the organization. He contends that employee engagement is a construct that groups five different dimensions: employee satisfaction, employee identification, employee commitment, employee loyalty, and employee performance.

After comparing various definitions used among scholars and practitioners, we found that the most common approach to defining engagement describes it as a positive state of mind that groups the feelings of vigor, dedication, and absorption at work (Schaufeli and Bakker, 2002). The Utrecht Work Engagement Scale (Schaufeli and Bakker, 2002) was developed and tested to measure employee engagement based on those three components and was identified to have valid and reliable psychometric properties. In agreement with Schaufeli and Bakker (2002), other researchers describe employee engagement as a feeling of satisfaction at the workplace that engages and energizes employees to work overtime and put in additional effort without being asked (Macey et al., 2009). Managing to turn disengaged employees into engaged employees is a challenge that organizations should not take lightly. Despite some improvements in the past decade, with a drop in the percentage of actively disengaged employees worldwide from $26 \%$ in 2009 to $17 \%$ in 2018, the Middle East and North Africa still have a higher percentage of disengaged employees (22\%; Gallup, 2017). This high level of disengagement in the region makes employees want to move to other countries for better and more satisfying opportunities or prefer working in the government sector due to cultural factors, the lack of support for human capital development, and low investment in the private sector. All these issues and implications feed into the increasing significance of building a high performing culture to grow the level of engaged employees and consequently improve business culture. 


\section{Organizational Climate}

Organizational climate is defined as the perception of employees toward behavioral norms, values, attitudes, and expectations shared among people within the organization (Sacher, 2010, p. 4). Griffin (2001) argues that organizational climate is the direct perception of employees on the work environment. Moghimi and Subramaniam (2013) stated that organizational climate is the set of values and beliefs that are not seen but inherent to employees' behavior. Subramani et al. (2016) define this construct as an important de. terminant that may have an impact on the psychological environment and employees' work-related attitude. In agreement, Vasudevan and Mahadi (2018) suggest that the organizational climate shapes employee understanding and behavior. While numerous studies have been conducted on organizational climate, their findings differ as the climate is specific and different to each organization depending on its size, structure, complexity, and so on (Lafta et al., 2016; Madhukar and Sharma, 2017). In this regard, the impact on employee work behavior and commitment levels differ accordingly.

Sainy and Arya (2017) reason that employees' perceptions of the organizational environment impact their performance levels. Therefore, the organizational climate has the power to affect employees positively or negatively and accordingly produce respective outcomes (Castro and Martins, 2010). Moreover, several studies show that business results are driven by employees' feelings about their work environment in the organization (Viswanathan, 2015; Lafta et al., 2016; Raja and Madhavi, 2019). Similarly, the literature links organizational climate with multiple variables such as organizational commitment (Berberoglu, 2018), job satisfaction (Ahmad et al., 2018), leadership style (Moslehpour et al., 2018), and perceived organizational performance (Berberoglu, 2018). Berberoglu (2018) states in her study that organizational climate has a direct and positive relationship with the perceived organizational performance of employees, while a less significant impact was associated with organizational commitment. Some researchers suggest that organizational climate is one of the most important and significant factors in a comfortable and enjoyable workplace (Jung, 2003). Hence, when organizations create a positive and supportive workplace where the policies and procedures are perceived as fair and enabling individual growth, employees' behaviors will be affected positively. Likewise, when employees' perceptions of organizational climate are negative, their behaviors are impacted negatively. Accordingly, the construct of climate is very much an individualistic perspective and should be assessed and measured on an employee level. 


\section{Organizational Justice}

Organizational justice has been studied on several occasions in the last three decades (Greenberg, 1987). Organizational justice is defined as the perception of employees towards the fairness of policies and procedures and the extent to which they are viewed as unbiased, objective, and ethically acceptable. Thus, the perception of fairness that each employee has is unique to them only and may not be a true and accurate reflection of reality. The construct of organizational justice is highly focused on the individual's personal assessment and perception of organizational decisions and outcomes (Choudhary et al., 2019). When these decisions and outcomes are perceived as fair and just, employees' behavior is affected positively and vice-versa. Furthermore, employees' perception of whether decisions are fair or unfair center on their own encounters in the organization which influence their behavior (Zeidan, 2006; Valentine, 2018).

The concept of justice stems from the theory of equity on motivation, which is built on the belief that employees will feel demotivated when they perceive inequity between the inputs and outputs observed between their coworkers and themselves (Adams, 1963). For a more in-depth understanding of the concept, academics divide the construct into three categories: distributive, procedural, and interactional justice (Cropanzano, Prehar and Chen, 2002).

Distributive justice refers to employees' perceptions of the fairness of organizational outcomes (Folger and Konovsky, 1989). Employees compare the ratio between their input and the output they receive (Adam, 1965; Leventhal, 1976). Furthermore, distributive justice considers the fairness in the distribution of rewards and resources among the individuals within an organization (Homans, 1989). As such, this construct of justice is both absolute and comparative, as it focuses on the perception of the employee but also on actual outcomes and decisions made by the organization such as a pay raise or a promotion.

Procedural justice refers to fairness in creating and implementing policies and procedures (Lind and Tyer, 1988). It focuses on the fairness of procedures and whether they are perceived as consistent, bias-free, accurate, and amendable to inputs (Leventhal, 1980; Thibaut, Walker, LaTour and Houldern, 1973; Konovsky, 2000). Folger and Greenberg (1985) argue that reward allocation policies significantly weigh on the perception of procedural fairness in an organization. Konovsky and Cropanzano (1991) show that procedural justice has a vital impact on numerous variables, including employees' commitment levels, job satisfaction, turnover intentions, and performance. The authors reason that procedural justice has such a high impact on employee outcomes that it 
leads them to have a higher sense of respect and care for the organization's performance and outcomes. Tyler and Lind (1992) also agree that when organizations implement fair procedures and foster the feelings of respect, acknowledgment, and appreciation, employees are more likely to engage in the organization and enhance performance.

Lastly, interactional justice is defined as the quality of treatment obtained from the management when implementing organizational procedures (Bies and Moag, 1986; Tyler and Bies, 1990). Moreover, interactional justice is considered a larger umbrella that groups interpersonal and informational justice (Colquitt, 2001). Interpersonal justice refers to the level of respect and communication displayed by supervisors to their employees, while informational justice refers to the honesty provided by supervisors when implementing these procedures (Bies and Shapiro, 2987; Greenberg and Cropanzano, 1993). While informational justice focuses on the relationship between employees and their supervisors, procedural and distributive justices center more on the relationship between employees and their organizations (Kim and Park, 2017). Moreover, distributive justice has a more significant impact on outcomes on a microlevel (Greenberg, 1990; Ghosh et al., 2014; McFarlin and Sweeney, 1992), whereas procedural justice is associated with having a more significant outcome on a macrolevel (Cropanzano and Folger, 1991; McFarlin and Sweeney, 1992; Saks, 2006). Accordingly, we expect distributive and procedural justices to have a positive impact on employee engagement.

Studies that examine the impact of organizational justice dimensions (distributive, procedural, and interactional) reveal that procedural and distributive justices are more significantly correlated to positive work behavior like engagement than interactional justice. Therefore, the framework of this study will focus on the concepts of distributive and procedural justice rather than interactional justice. It will highlight distributive justice as a key construct, because it focuses more on investigating the underlying relationship between the perceptions of employees to their organizations on a microlevel, and it will moreover incorporate the procedural justice dimension, as it investigates on a macrolevel the underlying relationship between the perceptions of employees and their organizations.

\section{Perceived Organizational Support}

Perceived Organizational Support (POS) is conceptually described as "the perception that employees have towards their organizations and the extent to which organizations value the contributions of their employees and care for their well-being" (Eisenberger et al., 1986, p. 501). As per the theory of reciprocity (Gouldner, 1960), employees will reciprocate the treatment they perceive and will produce positive outcomes when they 
believe that their organization is supportive, appreciates their contributions, and is interested in their welfare. Similarly, when employees perceive a negative treatment from their organizations, they will reciprocate with an unfavorable treatment (Rhoades and Eisenberger, 2002). This is consistent with the social exchange theory, which focuses on the core assumption that if a person puts in a certain amount of effort or investment into something, this person expects a corresponding return of effort and investment. In the same manner, when employees feel they are given organizational support, they will be more compelled to return this support by putting in more effort and commitment into work to realize this social exchange.

Zorlu et al. (2019) explain that this relationship between the employer and employee is based on impersonal or socio-emotional sources. In this regard, POS helps satisfy socio-emotional needs, such as approval, regard, emotional encouragement, and affiliation that drive the employee to identify with the organization (Kurtessis et al., 2015). This relationship also improves the morale of employees and leads to positive outcomes on both the departmental and organizational levels. Moreover, employees who feel that the organization is concerned about their well-being and values their contributions may have more trust in the decisions of the organization and engage in risk-taking actions (Neves, 2014). However, it is important to understand that this construct revolves around the notion of perception, which is naturally different and unique to each individual.

The sense of support will not be perceived with the same level among all employees and, consequently, the level of positive effect will be different to each person. Moreover, POS is linked to numerous positive employee behaviors, increased subjective well-being, and favorable work outcomes (Baran and Miller, 2012; Eisenberger and Stinglhamber, 2011; Kurtessis et al., 2015). Moreover, POS is linked to increased job satisfaction (Miao and Kim, 2010; Zumrah and Boyle, 2015; Günay, 2017), higher employee performance (DeConinck et al., 2018), and organizational commitment (Arshadi, 2011; Linda and Yonita, 2018). These relationships are due to the principle of reciprocity between the employee and the employer. In strong POS environments, employees strongly believe that the organization recognizes and rewards certain positive work outcomes, such as the increase of employee performance (Arshadi, 2011). As a result, employees with high POS are more likely to care for the organization, support its decisions, and further its organizational goals. 


\section{Theoretical Framework}

\section{Organizational Climate and Employee Engagement}

Organizational climate is the perception that employees have regarding procedures, policies, and practices within an organization. This construct has periodically been linked to employee engagement. On more than one occasion, researchers explored the relationship between the two constructs. Some researchers positively associate employee engagement to organizational climate as a direct relation (Geue, 2018), while others reveal that organizational climate affects employee engagement indirectly through other antecedents such as organizational leadership (Schein, 2004), organizational resources (Albrecht, Breidahl and Marty, 2018), or even perceived organizational support (Köse, 2016). Employees are more likely to engage and produce positive outcomes in a supportive environment, as a positive organizational climate preserves employee motivation and maintains high performance (Miller, 2002). Rabbanee et al. (2019) also present empirical evidence that supports a positive correlation between organizational climates for the initiative, psychological safety, and employee engagement. Moreover, they reveal that employee engagement has a positive and direct relationship to customer engagement, which has huge implications for business outcomes.

\section{Procedural Justice and Employee Engagement}

The link between organizational justice and employee work engagement has been examined on several occasions. Gupta and Kumar (2014) examine trust as a variable that mediates the relationship between justice and employee engagement. They empirically prove that higher levels of procedural justice lead to higher levels of vertical trust, which ultimately result in engaged employees. Work engagement was also assessed as a mediating factor between organizational justice and other positive job outcomes, such as job sharing and innovative work behavior (Woocheol and Park, 2017).

Researchers support a positive correlation between organizational justice and employee engagement. Many identify and confirm the impact of procedural justice on employee engagement while examining both the direct and indirect relations. Several researchers reveal substantial direct influence of organizational justice on employee engagement (Park, Song and Lim, 2016; O'Connor and Crowley-Henry, 2019), whereas others indicate the indirect effect of organizational justice on employee engagement through organizational identification (He, Zhu and Zheng, 2014). 


\section{Distributive Justice and Employee Engagement}

Distributive justice is an important construct of justice, commonly expressed when employees feel dissatisfied in their workplace. The perception of unfair distribution is usually displayed when employees feel that their inputs are not being rewarded or acknowledged as they should be (Adam, 1963). According to Biswas, Varma, and Ramaswami (2013), employees who feel that they were unjustly treated tend to display disengagement in their work and their workplace. These researchers suggest that organizations should focus on listening to their employees and showing concern and support. This implies that managers should be open to address and amend company policies and procedures when needed. Consequently, employees who perceive that the distribution of resources and rewards are just and fair will, in return, display engagement in their work, which will lead to their higher performance and productivity.

Distributive injustice causes employees to rebel against the outcomes of the implemented policies and procedures that they perceive as unjust, as argued by Özer, Uğurluoğlu, and Saygili (2017). The authors suggest that when employees perceive justice within their organizations, their behavior and engagement levels are positive. Furthermore, the authors argue that the most significant justice construct mediating employee engagement is created by procedural justice, followed by distributive justice.

\section{Perceived Organizational Support and Employee Engagement}

Scholarship shows that Perceived Organizational Support (POS) correlates with positive outcomes in the workplace. Among these correlations, various studies show employee engagement to be a significant outcome (Kralj and Solnet, 2011; Dai and Qin, 2016; Chass and Balu, 2018). Moreover, Chass and Balu (2018) find a strong and positive correlation between POS and employee engagement. Furthermore, a study that analyzes this correlation on a generational level found that the influence of POS on millennials and non-millennials is equally important and significant to both cohorts (Kralj and Solnet, 2011). In our developed model, we propose that the relationship between POS and employee engagement will be positive and that this relationship will also be mediated by organizational climate.

Subsequent to the previous discussion, we make the following propositions regarding organizational climate, perceived organizational support, procedural justice, distributive justice, and employee engagement (Figure 1): 
Proposition 1. A more favorable organizational climate will create higher levels of employee engagement.

Proposition 2. Higher levels of perceived organizational support will contribute to a more positive organizational climate, which will in turn result in more engaged employees.

Proposition 3. An increase in procedural justice will promote positive employee engagement.

Proposition 4. Higher levels of distributive justice will lead to higher levels of employee engagement.

Proposition 5. Higher levels of perceived organizational support will foster higher levels of employee engagement.

Figure 1. Conceptual Model

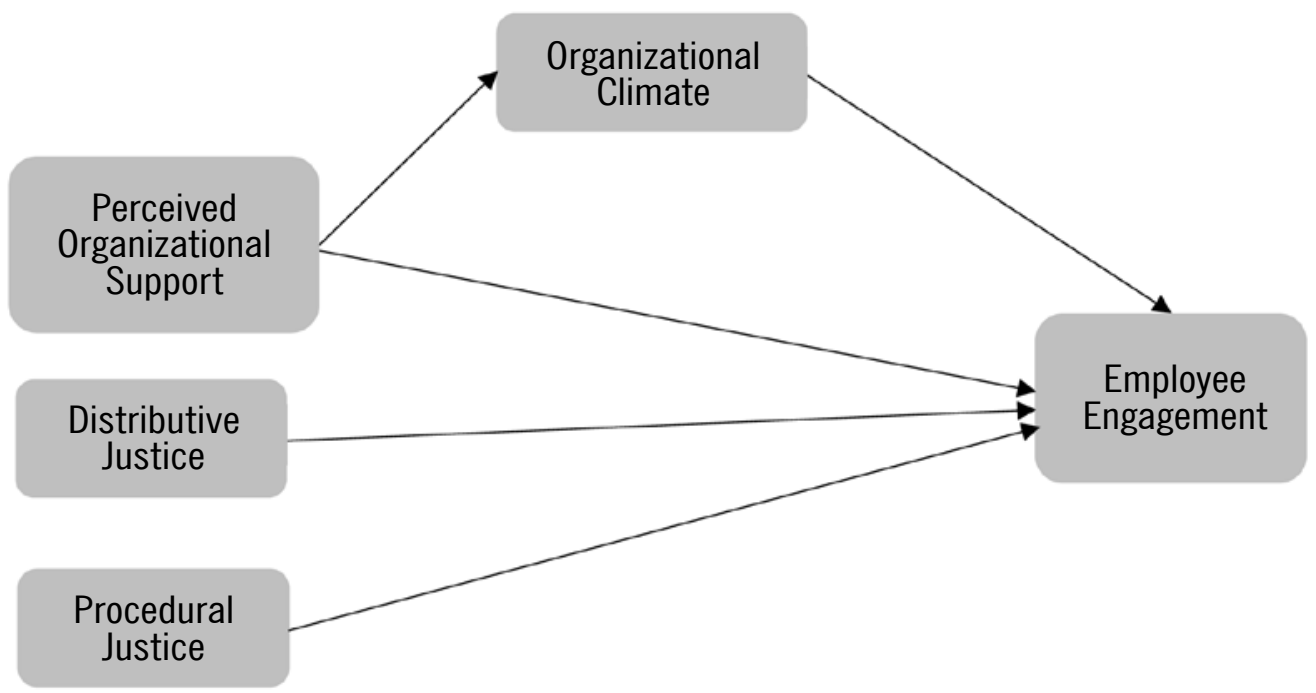

Source: own elaboration.

\section{Conclusions and Directions for Future Research}

Attaining high levels of employee engagement continues to be a challenge for most organizations on a global level in the highly competitive and dynamic economy. Engaging the workforce has never been more important or vital to the survival of companies. Engagement is linked to the overall organizational performance, as it impacts the behavior of employees and their outcomes. 
Employees are the company's biggest asset, and without the ability to engage them, their productivity and performance will decrease, thus resulting in poor business outcomes (Kim et al., 2019). Hence, HR professionals and managers must understand the needs, expectations, and wants of employees so as to learn how to engage them and maintain an engaged workforce. For that, HR professionals need to first understand employees' perceptions toward their supervisors and their organization, as there exists a clear gap between the expectations of HR professionals and employees (Zeidan, 2006).

Xiong and Wen (2020) explore the role of employee engagement in turnover rates and behavioral outcomes. Their study suggests that turnover rates and employee engagement levels are negatively correlated. Moreover, the authors suggest that turnover rates have a significant negative correlation with organizational citizenship behavior and a significantly positive correlation with counterproductive work behavior. They recommend that organizations implement an employee retention strategy to foster more organizational citizenship behavior and demote counterproductive work behavior, thus leading to higher employee engagement levels.

Moreover, managers and direct supervisors have a great influence on the engagement levels of employees. It is important for managers to understand the crucial role they play in shaping employee perception and experience so as to learn the impact they have on employee engagement (Reina et al., 2018). Furthermore, the implementation of managerial leadership models can positively impact organizational performance measures such as employee engagement, as proposed by Prince and Mihalicz (2019). The authors suggest that managers must undergo managerial effectiveness training to improve their managerial styles and consequently improve employee engagement.

First, when it comes to organizational climate and employee engagement, the key consideration for employers is to create a positive environment for employees, in which their hard work is acknowledged, rewarded, and appreciated. Geue (2018) supports this argument and highlights the importance of managerial involvement in achieving higher levels of employee engagement. He states that managers can motivate their team members by cultivating a supportive culture that creates more engagement and produces greater results.

Second, the literature suggests that perceived organizational support has a strong and positive correlation with employee engagement. From a practical perspective, it is important for managers to understand the type of support that is most influential to achieving greater employee engagement. Managers should demonstrate support to the employees at all times; this is particularly important when organizations undergo a transition 
such as a merger or deal with an external force such as an economic crisis. Managerial involvement, support, and reassurance provided to employees - especially during trying times - will determine how employees behave, perform, and approach the organization after a difficult period.

Third, the perception of justice has important practical implications. Employee perception of justice is vital, as it highly affects their behaviors and outcomes. Managers must be more transparent in their communication with employees about the policies and procedures, which must be consistent, bias-free, ethical, and amendable (Cloquitt et al., 2005). Furthermore, managers influence employees to engage more when the distribution of resources and rewards is equal and fair. We encourage managers to explain and justify these distributions so that employees can perceive them as fair and just.

This research adds value to both the theoretical and practical perspectives. From the theoretical perspective, our study provides a primary insight into the relationships between procedural justice, organizational climate, perceived organizational support, and employee engagement.

Future research can develop further insight into how to foster higher levels of employee engagement by testing the conceptual framework and comparing findings in both the private and public sectors. Moreover, researchers can look at other variables or mediating effects that may impact employee engagement, such as employee satisfaction, organizational citizenship behavior, and motivation. For example, research can benefit from scrutinizing the concept of trust and testing the mediating effect of this concept in the organizational justice-employee engagement relationship.

\section{References}

Ahmad, K.Z.B., Jasimuddin, S.M. and Kee, W.L. (2018). Organizational climate and job satisfaction: do employees' personalities matter? Management Decision, 56(2), 421-440,

https://doi.org/10.1108/MD-10-2016-0713.

Aktouf, O. (1992). Management and Theories of Organizations in the 1990s: Toward a Critical Radical Humanism? The Academy of Management Review, 17(3), 407, https://doi.org/10.2307/258717.

Albrecht, S., Breidahl, E. and Marty, A. (2018). Organizational resources, organizational engagement climate, and employee engagement. Career Development International, 23(1), 67-85, https://doi.org/10.1108/CDI-04-2017-0064.

Alfes, K., Shantz, A.D., Truss, C. and Soane, E.C. (2013). The link between perceived human resource management practices, engagement and employee behaviour: a moderated mediation model. The International Journal of Human Resource Management, 24(2), 330-351, https://doi.org/10.1080/09585192.2012.679950. 
Abubakr, S. and Majid, K. (2013). Organizational justice, commitment and performance in developing countries: The case of the UAE, https://doi.org/10.1108/01425451311279438.

Ali, A. and Bukhari, I. (2017). Relationship of Organizational Justice and its Dimension with Turnover Intention among Employees of Electronic Media. Bahria Journal of Professional Psychology, 16(2), 59-69.

Arya, R. and Sainy, M. (2017). To Study the Impact of Organizational Climate on Employee Engagement in the Banking Sector with Special Reference to State Bank of India, Indore. Prestige e-Journal of Management and Research, 4(1), 64-81.

Bailey, A.A., Albassami, F. and Al-Meshal, S. (2016). The roles of employee job satisfaction and organizational commitment in the internal marketing-employee bank identification relationship. International Journal of Bank Marketing, 34(6), 821-840, https://doi.org/10.1108/IJBM-06-2015-0097.

Baran, B., Rhoades, L. and Miller, L. (2012). Advancing organizational support theory into the twenty-first century world of work. Journal of Business and Psychology, 27(2), 123-147, https://doi.org/10.1007/s10869-011-9236-3.

Berberoglu, A. (2018). Impact of organizational climate on organizational commitment and perceived organizational performance: Empirical evidence from public hospitals. BMC Health Services Research, 18(1), https://doi.org/10.1186/s12913-018-3149-z.

Bhappu, A.D. and Schultze, U. (2018). Implementing an Organization-sponsored Sharing Platform to Build Employee Engagement. MIS Quarterly Executive, 17(2), 109-120.

Biswas, Soumendu; Varma, Arup; and Ramaswami, Aarti (2013). Linking Distributive and Procedural Justice to Employee Engagement Through Social Exchange: A Field Study in India. The International Journal of Human Resource Management, 24(8), 1570-1587, https://doi.org/10.1080/09585192.2012.725072.

Branham, L. (2005). The 7 Hidden Reasons Employees Leave: How to Recognize the Subtle Signs and Act Before It's Too Late. United States: American Management Association.

Castro, M.L. and Martins, N. (2010). The relationship between organisational climate and employee satisfaction in a South African information and technology organisation. SA Journal of Industrial Psychology, 36(1), https://doi.org/10.4102/sajip.v36i1.800.

Chass, M.S. and Balu, L. (2018). Impact of Perceived Organisational Support on Employee Engagement at Tas Impex Private Limited, Hyderabad. International Journal of Engineering Technology Science and Research, 5(3), 334-339, http://ijetsr.com/images/short_pdf/1520824896_334-339chd914_ijetsr.pdf.

Choudhary, N., Philip, J. and Deswal, R. (2013). Impact of Organizational Justice on Organizational Effectiveness. Industrial Engineering Letters, 1(3), 18-24.

Choudhury, S. and Mohanty, M.K. (2019). Drivers of Employee Engagement - a Chronological Literature Review Excluding India. Journal of Strategic Human Resource Management, 8(1), 32-46.

Christian, M.S., Garza, A.S. and Slaughter, J.E. (2011). Work engagement: a quantitative review and test of its relations with task and contextual performance. Personnel Psychology, 64(1), 89-136, https://doi.org/10.1111/j.1744-6570.2010.01203.x.

Colquitt, J.A. (2001). On the dimensionality of organizational justice: A construct validation of a measure. Journal of Applied Psychology, 86, 386-400, https://doi.org/10.1037/0021-9010.86.3.386.

Crabtree, S. (October 2013). Worldwide, 13\% of Employees Are Engaged at Work, https://news.gallup.com/poll/165269/worldwide-employees-engaged-work.aspx.

Cropanzano, R. and Folger, R. (1991). Procedural justice and worker motivation. In: R.M. Steers and L.W. Porter (eds.), Motivation and work behavior. New York: McGraw-Hill. 
Dai, K.L. and Qin, X.Y. (2016). Perceived Organizational Support and Employee Engagement: Based on the Research of Organizational Identification and Organizational Justice. Open Journal of Social Sciences, 4(12), 46-57, https://doi.org/10.4236/jss.2016.412005.

DeConinck J.B., Moss, H.K. and Deconinck, M.B. (2018). The Relationship between Servant Leadership, Perceived Organizational Support, Performance, and Turnover among Business to Business Salespeople. Global Journal of Management and Marketing, 2(1), 38-52.

DeConinck, J.B. and Stilwell, C.D. (2004). Incorporating organizational justice, role states, pay satisfaction and supervisor satisfaction in a model of turnover intentions. Journal of Business Research, 57(3), 225-231, https://doi.org/10.1016/S0148-2963(02)00289-8.

Eisenberger, R. and Stinglhamber, F. (2011). Perceived Organizational Support: Fostering Enthusiastic and Productive Employees. Washington, DC: American Psychological Association, https://doi.org/10.1037/12318-000.

Eisenberger, R., Armeli, S., Rexwinkel, B., Lynch, P.D. and Rhoades, L. (2002). Reciprocation of perceived organizational support. Journal of Applied Psychology, 86(1), 42-51, https://doi.org/10.1037/0021-9010.86.1.42.

Eisenberger, R., Huntington, R., Hutchison, S. and Sowa, D. (1986). Perceived organizational support. Journal of Applied Psychology, 17(3), 500-507, https://doi.org/10.1037/0021-9010.71.3.500.

Folger, R. and Greenberg, J. (1985). Procedural justice: An interpretational analysis of personnel systems. Research in Personnel and Human Resources Management, 3(1), 141-183.

Luthans, F. and Peterson, S.J. (2002). Employee engagement and manager self-efficacy. Journal of Management Development, 21(5), 376-387, https://doi.org/10.1108/02621710210426864.

Gallup Organization (2017). State of The Global Workplace. Gallup Management Journal. https://www.gallup.com/workplace/238079/state-global-workplace-2017.aspx (8.02.2019).

Geue, P.E. (2018). Positive practices in the workplace: Impact on team climate, work engagement, and task performance. Journal of Applied Behavioral Science, 54(3), 272-301, https://doi.org/10.1177/0021886318773459.

Ghosh, P., Rai, A. and Sinha, A. (2014). Organizational justice and employee engagement: Exploring the linkage in public sector banks in India. Personnel Review, 43(4), 628-652, https://doi.org/10.1108/PR-08-2013-0148.

Gouldner, A.W. (1960). The norm of reciprocity: A preliminary statement. American Sociological Review, 25(2), 161-178, https://doi.org/10.2307/2092623.

Greenberg, J. (1987). A Taxonomy of Organizational Justice Theories. Academy of Management Review, 12(1), 9-22, https://doi.org/10.5465/amr.1987.4306437.

Greenberg, J. and Folger, R. (1983). Procedural justice, participation and the fair process effect in groups and organizations. In: P.B. Paulus (ed.), Basic group processes. New York: Springer-Verlag, 235-256, https://doi.org/10.1007/978-1-4612-5578-9_10.

Griffin, L. (2001). Job satisfaction among detention officers: Assessing the relative contribution of organizational climate variables. Journal of Criminal Justice, 29(3), 219-232, https://doi.org/10.1016/S0047-2352(01)00086-1.

Günay, G.Y. (2017). The Relationship among Perceived Organizational Support, Job Satisfaction, and Alienation: An Empirical Study on Academicians. International Journal of Business and Social Science, 8(1), 96-106.

Gupta, M. and Kumar, Y. (2015). Justice and employee engagement: Examining the mediating role of trust in Indian B-Schools. Asia-Pacific Journal of Business Administration, 7(1), 89-103, https://doi.org/10.1108/APJBA-04-2014-0048. 
Guzzo, R.A., Noonan, K.A. and Elron, E. (1994). Expatriate managers and the psychological contract. Journal of Applied Psychology, 79(4), 617-626, https://doi.org/10.1037/0021-9010.79.4.617.

Halbesleben, J.R.B. (2010). A meta-analysis of work engagement: relationships with burnout, demands, resources, and consequences. In: A.B. Bakker and M.P. Leiter (eds.), Work Engagement: A Handbook of Essential Theory and Research. New York: Psychology Press.

He, H., Zhu, W. and Zheng, X. (2014). Procedural Justice and Employee Engagement: Roles of Organizational Identification and Moral Identity Centrality. Journal of Business Ethics, 122(4), 681-695, https://doi.org/10.1007/s10551-013-1774-3.

Miller J. (2002). Creating a Work Climate That Motivates Staff and Improves Performance. Management Sciences for Health, 11(3), 1-22.

Jung, D.I., Chow, C. and Wu, A (2003). The role of transformational leadership in enhancing organizational innovation: Hypotheses and some preliminary findings. Leadership Quarterly, 14(1), 525-544, https://doi.org/10.1016/S1048-9843(03)00050-X.

Kalay, F. (2016). The Impact of Organizational Justice on Employee Performance: A Survey in Turkey and Turkish Context. International Journal of Human Resource Studies, 6(1), 1-20, https://doi.org/10.5296/ijhrs.v6i1.8854.

Kim, W., Han, J.H. and Park, J. (2019). Is the role of work engagement essential to employee performance or a 'nice to have'? Sustainability, 11, 1050, https://doi.org/10.3390/su11041050.

Konovsky, M. and Cropanzano, R. (1991). Perceived fairness of employee drug testing as a predictor of employee attitudes and performance. Journal of Applied Psychology, 76(5), 698-707, https://doi.org/10.1037/0021-9010.76.5.698.

Köse, A. (2016). The Relationship between Work Engagement Behavior and Perceived Organizational Support and Organizational Climate. Journal of Education and Practice, 7(27), 42-52.

Kralj, A. and Solnet, D. (2011). The influence of perceived organizational support on engagement: A cross-generational investigation in the hospitality industry. 2011 ICHRIE Conference.

Krueger, J. and Killham, E. (2007). The innovation equation. Gallup Management Journal, http://gmj.gallup.com/content/27145/innovation-equation.aspx.

Kumar, V. and Pansari, A. (2015). Measuring the benefits of employee engagement. MIT Sloan Management Review, 56(4), 67.

Kurian, D. (2018). Organizational Justice: Why Does It Matter for HRD. Journal of Organizational Psychology, 18(2), 11-22, https://doi.org/10.33423/jop.v18i2.1296.

Kurtessis, J.N., Eisenberger, R., Ford, M.T., Buffardi, L.C., Stewart, K.A. and Adis, C.S. (2017). Perceived organizational support: A meta-analytic evaluation of organizational support theory. Journal of Management, 43(6), 1854-1884, https://doi.org/10.1177/0149206315575554.

Lafta, A., Man, N., Salih, J., Samah, B., Nawi, N. and Yusof, R. (2016). A Need for Investigating Organizational Climate and Its Impact on the Performance. European Journal of Business and Management, 8(3), 136-142.

Lodha, D. and Pathak, K. (2017). Eeffect of psychological contract on employee engagement. Rising A Journal of Researches, 11(1), 5-14.

Macey, W.H., Schneider, B., Barbera, K.M. and Young, S.A. (2009). Employee Engagement: Tools for Analysis, Practice, and Competitive Advantage. Malden, MA: Wiley-Blackwell, https://doi.org/10.1002/9781444306538.

Madhukar, V. and Sharma, S. (2017). Organizational Climate: A Conceptual Perspective. International Journal of Management, IT and Engineering, 7(8), 276-293.

Marciano, P. (2010). Carrots and Sticks Don't Work: Build a Culture of Employee Engagement with the Principles of Respect. New York: McGraw Hill Professional. 
McFarlin, D.B. and Sweeney, P.D. (1992). Distributive and procedural justice as predictors of satisfaction with personal and organizational outcomes. Academy of Management Journal, 35(3), 626-637, https://doi.org/10.2307/256489.

Miao, R. (2010). Perceived Organizational Support, Job Satisfaction and Employee Performance: A Chinese Empirical Study. Journal of Service Science and Management, 3(2), 257-264, https://doi.org/10.4236/jssm.2010.32032.

Moghimi, S. and Subramaniam, I.D. (2013). Employees' Creative Behavior: The Role of Organizational Climate in Malaysian SMEs. International Journal of Business and Management, 8(5), 1-13, https://doi.org/10.5539/ijbm.v8n5p1.

Mohanty, M.M. and Choudhury, S. (2018). Employee Engagement and Productivity - Linking connectivity from manufacturing industry perspective. International Journal of Multidisciplinary, 3(9), 592-602.

Moslehpour, M., Altantsetseg, P., Mou, W. and Wong, W.-K. (2019). Organizational Climate and Work Style: The Missing Links for Sustainability of Leadership and Satisfied Employees. Sustainability, 11(1), 125, https://doi.org/10.3390/su11010125.

Muthia, R.L. and Yonita, R. (2018). The Effect of Job Satisfaction and Perceived Organizational Support on Organizational Commitment of Banks' Employees in Padang. Advances in Economics, Business and Management Research, 57(PICEEBA 2018), 216-222.

Naidoo, V., Abarantyne, I. and Rugimbana, R. (2019). The impact of psychological contracts on employee engagement at a university of technology. South African Journal of Human Resource Management, 17(1), 1683-7584, https://doi.org/10.4102/sajhrm.v17i0.1039.

Nasrin Arshadi, N. (2011). The relationships of perceived organizational support (POS) with organizational commitment, in-role performance, and turnover intention: Mediating role of felt obligation. Procedia - Social and Behavioral Sciences Procedia - Social and Behavioral Sciences, 30(1), 1103-1108, https://doi.org/10.1016/j.sbspro.2011.10.215.

Neves, P. and Eisenberger, R. (2014). Perceived organizational support and risk taking. Journal of Managerial Psychology, 29(2), 187-205, https://doi.org/10.1108/JMP-07-2011-0021.

O'Connor, E. and Crowley-Henry, M. (2019). Exploring the Relationship between Exclusive Talent Management, Perceived Organizational Justice and Employee Engagement: Bridging the Literature. Journal of Business Ethics, 156(1), 903-917, https://doi.org/10.1007/s10551-017-3543-1.

Özer, Ö, Uğurluoğlu, Ö. and Saygili, M. (2017). Effect of Organizational Justice on Work Engagement in Healthcare Sector of Turkey. Journal of Health Management, 19(1). 73-83.

Özşahin, M. and Yürür, S. (2018). The Effect of Organizational Structure on Organizational Justice Perceptions of Employees. International Journal of Organizational Leadership, 7(4), 440-453, https://doi.org/10.33844/ijol.2018.60290.

Park, Y., Song, J.H. and Lim, D.H. (2016). Organizational justice and work engagement: the mediating effect of self-leadership. Leadership \& Organization Development Journal, 37(6), 711-729, https://doi.org/10.1108/LODJ-09-2014-0192.

Prince, P.N. and Mihalicz, D.W. (2019). Manager Effectiveness, Employee Engagement, and Client-Based Organizational Outcomes in a Mental Health Setting. Healthcare Management Forum, 32(2), 84-87, https://doi.org/10.1177/0840470418814854.

Punwatkar, S. and Verghese, M. (2018). The Moderating Role of Organizational Climate in Competency-Performance Relationship: A Study on Salespersons in Central India. IUP Journal of Organizational Behavior, 17(4), 36-57. 
Rabbanee, K.F., Haque, M.M., Banik, S. and Islam, M.M. (2019). Managing engagement in an emerging economy service. Journal of Service Theory and Practice, 29(5/6), 610-638, https://doi.org/10.1108/JSTP-12-2018-0276.

Raja, S. and Madhavi, C. (2019). Influence of Organizational Climate on Employee Performance in Manufacturing Industry. Suraj Punj Journal for Multidisciplinary Research, 9(3), 146-157.

Reina, C.S., Rogers, K.M., Peterson, S.J., Byron, K. and Hom, P.W. (2018). Quitting the Boss? The Role of Manager Influence Tactics and Employee Emotional Engagement in Voluntary Turnover. Journal of Leadership \& Organizational Studies, 25(1), 5-18, https://doi.org/10.1177/1548051817709007.

Robinson, D., Perryman, S., and Hayday, S. (2004). The Drivers of Employee Engagement Report 408. Institute for Employment Studies, UK.

Sacher, A. (2010). Organization climate and managerial effectiveness. Mumbai: Himalaya Publishing House.

Saks, A.M. (2006). Antecedents and consequences of employee engagement. Journal of Managerial Psychology, 21(7), 600-619, https://doi.org/10.1108/02683940610690169.

Saqib Khan, I., Kamal, S., Ullah, Z., Khan, S., Ullah, M. and Pervez, A. (2017). Muhammad \& saqib, Muhammad. The Impact of Distributive, Procedural and Interactional Justice on Organizational Commitment. International Affairs and Global Strategy, 55(1), 14-19.

Schaufeli, W.B., Salanova, M., Gonzalez-Roma, V. and Bakker, A.B. (2002). The measurement of engagement and burnout: a two sample two-sample confirmatory factor analytic approach. Journal of Happiness Studies, 3(1), 71-92, https://doi.org/10.1023/A:1015630930326.

Schein, E.H. (2004). Organizational culture and leadership (3rd ed.). San Francisco: Jossey-Bass.

Schminke, M., Cropanzano, R. and Rupp, D.E. (2002). Organization structure and fairness perceptions: The moderating effects of organizational level. Organizational Behavior and Human Decision Processes, 89(1), 881-905, https://doi.org/10.1016/S0749-5978(02)00034-1.

Schneider, B. and Barbera, K.M. (2014). The Oxford Handbook of Organizational Climate and Culture, Oxford: Oxford University Press, https://doi.org/10.1093/oxfordhb/9780199860715.001.0001.

Schneider, B., Ehrhart, M.G. and Macey, W.H. (2011). Perspectives on organizational climate and culture. In: S. Zedeck (ed.), APA handbook of industrial and organizational psychology, Vol 1: Building and developing the organization. Washington, DC, US: American Psychological Association, https://doi.org/10.1037/12169-012.

Scott, D. (2017). Are non-engaged employees sabotaging your organization? Casino Journal, 30(10), 12.

Smith, M. and Bititci, U.S. (2017). Interplay between performance measurement and management, employee engagement and performance. International Journal of Operations \& Production Management, 37(9), 1207, https://doi.org/10.1108/IJOPM-06-2015-0313.

Solmaz, M. and Subramaniam, I. (2013). Employees' Creative Behavior: The Role of Organizational Climate in Malaysian SMEs. International Journal of Business and Management, 8(5), 1-12, https://doi.org/10.5539/ijbm.v8n5p1.

Subramani, A.K., Jan, N.A., Gaur, M. and Vinodh, N. (2016). Impact of organizational climate on organizational citizenship behaviour with respect to automotive industries at Ambattur industrial estate, Chennai. International Journal of Applied Business and Economic Research, 1(8), 6391-6408.

Suliman, A. and Al Kathairi, M. (2013). Organizational justice, commitment and performance in developing countries. Employee Relations, 35(1), 98-115, https://doi.org/10.1108/01425451311279438.

Sutanto, E.M., Scheller-Sampson, J. and Mulyono, F. (2018). Organizational Justice Work Environment and Motivation. International Journal of Business \& Society, 19(2), 313-322. 
Tyler, T. and Lind, E.A. (1992). A relational model of authority in groups. In: M.P. Zanna (ed.), Advances in Experimental Social Psychology, 25(1), 115-191. San Diego, CA: Academic Press, https://doi.org/10.1016/S0065-2601(08)60283-X.

Valentine, M. (2018). When Equity Seems Unfair: The Role of Justice Enforceability in Temporary Team Coordination. Academy of Management Journal, 61(6), 2081-2105, https://doi.org/10.5465/amj.2016.1101.

Vasudevan, H. and Mahadi, N. (2019). Assessing the Mediating Effect of Organizational Climate in the Context of Malaysian Banking Industry. Journal of Entrepreneurship and Business, 7(1), 10-26, https://doi.org/10.17687/JEB.0701.02.

Viswanathan, R. (2015). A Study on the Impact of Organizational Climate on Project Success Among Software Engineers in It Sector. Paripex - Indian Journal of Research, 4(7), 387-390.

Woocheol Kim and Park, J. (2017). Examining Structural Relationships between Work Engagement, Organizational Procedural Justice, Knowledge Sharing, and Innovative Work Behavior for Sustainable Organizations. Sustainability (2071-1050), 9(2), 205, https://doi.org/10.3390/su9020205.

Xiong, R. and Wen, Y. (2020). Employees' turnover intention and behavioral outcomes: The role of work engagement. Social Behavior and Personality: An International Journal, 48(1), e8609, https://doi.org/10.2224/sbp.8609.

Zeidan, S. (2006). The relationship between high commitment management and employee attitudes and behaviours: the role of psychological contract fulfilment and justice, $\mathrm{PhD}$ thesis, Victoria University.

Zelles, R. (2015). Better Profitability through Higher Employee Engagement in the Knowledge Worker Age. Journal of HRM, 18(2), 62-72.

Zorlu, Ö., Avan, A. and Baytok, A. (2019). Perceived Organizational Support and Organizational Identification: The Mediating Role of Fit to Organization. Turizm Akademik Dergisi, 5(1), 277-291.

Zumrah, Abdul and Boyle, S. (2015). The effects of perceived organizational support and job satisfaction on transfer of training. Personnel Review, https://doi.org/10.1108/PR-02-2013-0029. 